\title{
LIGHT SCATTERING SENSOR FOR RAPID DETECTION OF BACILLUS CEREUS IN CHICKEN MEATS
}

\author{
Maha Usama Abdalhaseib ${ }^{a, b}$ and Arun K. Bhunia ${ }^{a, c}$, \\ a.Molecular Food Microbiology Laboratory, Department of Food Science, Purdue University, West Lafayette, IN, USA \\ b.Food Hygiene Department, Assiut University, Egypt \\ c.Department of Comparative Pathobiology, Purdue University, West Lafayette, IN, US
}

\begin{abstract}
Bacillus cereus is an opportunistic pathogen causing food poisoning, manifested by diarrhea or emetic illnesses. BARDOT (BActerial Rapid Detection using Optical scattering Technology) directly capturing phenotypic characteristics of colonies following standard agar plating, providing non-destructive, high-throughput analysis and real-time detection of colonies on agar plate without any labeling reagents or probes. This study implement light scattering sensor in detection and identification of B. cereus on genus level in mixed cultures and in artificially inoculated chicken samples using PRM (phenol red mannitol) agar. Software analysis and PCR confirmation showed that BARDOT successfully detect $100 \%$ of $B$. cereus in mixed culture and $>90 \%$ of artificially inoculated chicken samples. This results demonstrates that BARDOT could be used as a screening tool to identify Bacillus cereus from other pathogens and background flora on PRM agar.
\end{abstract}

Keywords: Bacillus Cereus, light scattering sensor, BARDOT and Chicken.

\section{INTRODUCTION}

B. cereus is a Gram-positive, sporeforming, flagellated, rod-shaped bacterium. Because of its ubiquitous nature, B. cereus is widespread in nature and commonly found in air, soil and water (Vilain et al., 2006). It can easily be spread to the foods of plant origin and through cross contamination to other foods such as milk, meat and meat products (Granum 1994 and Larsen and Jorgensen, 1997). Nowadays, meat and meat products are the most important incriminated food in $B$. cereus food poisoning as contamination and multiplication of $B$. cereus organisms in raw meat and their products is of major concern as public health hazard. B. cereus Spores are resistant to ecological stressors more than the vegetative form due to their metabolic dormancy and substantial nature (Jenson and Moir, 2003).

$B$. cereus is the etiologic agent of two types of food associated illnesses emetic and diarrhoeal type. The emetic illness is a food intoxication resulted from ingestion of a cyclic peptide toxin called cereulide formed during growth of $B$. cereus organisms in food; this form is characterized by a short incubation period and recovery time. The signs appears 2$5 \mathrm{~h}$ following ingestion of contaminated food includes nausea, vomiting and abdominal cramping with recovery usually within 6-24 hours (Schoeni and Wong, 2005 and Senesi and Ghelardi, 2010).

The diarrhoeal illness is caused by enterotoxins produced by $B$. cereus growth inside the host small intestine. The incubation 
period is $8-16$ hours and the illness usually lasts within 12-14 hours, however it might continue for several days. Signs are usually mild with abdominal cramps, watery diarrhoea and nausea (Granum, 2007). Few cases recorded both types of toxin are produced (Montville and Matthews 2005). However neither of illness is considered life threatening illness (Jenson and Moir, 2003). B. cereus food poisoning occur as the spore survive the cooking temperature or as a result of poor temperature control during the processing and holding of the food resulting in bacterial vegetation and multiplication. Ingestion of food contaminated with $10^{5}-10^{6} \quad$ B. cereus $/ g$ resulted in food poisoning illness (Kramer and Gilbert 1989). The incidence of $B$. cereus has been reported in meat and meat products (Bachhil and Negi, 1984; Bachhil and Jaiswal, 1988; Willayat et al., 2007; Hafiz et al., 2012 and Rao et al., 2012). Food poisonings cases resulted from $B$. cereus in different countries is not a reportable illness and is not always diagnosed (Kotiranta et al., 2000).

Detection and identification of $B$. cereus from food samples generally based on three chief methods basically, first: the traditional culture method based on agar medium, colony morphology and further biochemical confirmation. Secound: immunoassays using specific antibodies targeting either the cells or toxins (Chen and Ding, 2004; Dietrich et al., 2005 and Moravek et al., 2006), and third is molecular techniques as PCR that identifies toxin production genes (Fricker et al., 2007; Martinez-Blanch et al., 2009 and Wehrle et al., 2009). However, many limitation facing these methods leading to false negative results due to matrix associated inhibitors and also may not differentiate living from dead bacteria (Hedman and Radstrom, 2013), and do not allow injured cell recovery due to lack of enrichment step.

Therefore, continuous looking for an alternative techniques, especially those that combine the advantage of recovery of the target pathogen in addition to being highly specific, rapid, and sensitive is a major challenging task for regulatory agencies and food industries to control food borne pathogens. Currently optical biosensors are of increasing interest as they provide fast, non-destructive, sensitive, and specific results (Bhunia, 2011, 2014; Homola, 2008 and Sharma and Mutharasan, 2013). Light scattering BARDOT greatly offer a high throughput screening tools to test food samples in competitive time compared to other conventional methods and without the need for labeling reagents (Bhunia, 2014).

Therefore, the aim of this study was to investigate implementation of BARDOT optical sensors for specific and accurate detection of $B$. cereus in mixed cultures and in artificially inoculated chicken samples.

\section{MATERIALS AND METHODS}

\subsection{Bacterial cultures and growth media}

$B$. cereus and non-Bacillus cultures (Escherichia coli O157:H7, Salmonella. Typhimurium, Salmonella. Enteritidis PT21, Citrobacter freundii and Hafnia alvei) were used in the experiments. All cultures were grown from $80-{ }^{\circ} \mathrm{C}$ frozen glycerol stocks by inoculation into brain heart infusion broth (BHI, Becton Dickinson (BD), flowed by overnight incubation at $37^{\circ} \mathrm{C}$ in a shaker incubator. To develop a light-scatter image library, selective agar phenol red mannitol (PRM; BD) dehydrated media were prepared as the manufacturer's instruction. 


\subsection{Light scattering sensor based detection}

All laboratory cultures were overnight grown in BHI broth, serially diluted in $20 \mathrm{mM}$ phosphate buffered saline (PBS), $\mathrm{pH}$ 7.4, plated onto phenol red mannitol agar (PRM) and incubated at $37^{\circ} \mathrm{C}$ for $7: 8 \mathrm{~h}$ or to achieve a colony diameter of about $1 \mathrm{~mm}(0.8 \pm 0.2 \mathrm{~mm})$, measured under a phase-contrast microscope (Leica,Wetzlar, Germany) Leica Application Suite version 4.2.0 (Leica Microsystems, Switzerland). Plates were screened using BARDOT machine (Figure 1), reported previously (Banada et al., 2009 and Singh et al., 2015) and the colony scatter patterns were matched against the Bacillus- non Bacillus scatter image libraries generated in our previous study (Singh et al., 2015). and the results were presented as positive predictive values percent (PPV\%) (Singh et al., 2014).

\subsection{BARDOT instrumentation and image analysis.}

BARDOT (bacterial rapid detection using optical scattering technology) is a laser based forward light scattering sensor that utilizes a 635-nm red diode laser beam to capture scatter signatures of individual $\sim 1-\mathrm{mm}$ diameter colonies for real-time interrogation on the plate (Bhunia, 2011). The method is used for direct capturing of phenotypic characteristics of bacterial colonies obtained by classical microbiological methods to provide nondestructive, high throughput analysis and realtime detection on agar plates without any labeling reagents or probes (Banada et al., 2009).

\subsection{Detection and identification of $B$. cereus in Mixed cultures.}

Overnight grown $B$. cereus were mixed in equal amount individually and collectively with each of Citrobacter freundii, E. coli
O15:7H7 or S. Enteritidis PT21 and Hafnia alvei then $100 \mathrm{ul}$ aliquot was serially diluted in PBS and surface plated on PRM agar till the colony size of $1 \mathrm{~mm}$ for BARDOT analysis and The colony scatter patterns matched against Bacillus and non Bacillus scatter image libraries using DOTBAR software with further PCR confirmation for the BARDOT identified colonies.

\subsection{Detection and identification of $B$. cereus from artificially inoculated food samples.}

Chicken breast samples were purchased from local grocery stores in West Lafayette, Indiana and $30 \mathrm{~g}$ of chicken samples were artificially inoculated with $100 \mu \mathrm{l}$ overnight grown B. cereus ATCC14579, placed in a biosafety cabinet for 24h. Samples were transferred into stomacher bags (Seward, Cincinnati, OH, USA), resuspended in $270 \mathrm{ml}$ of $20 \mathrm{mM}$ PBS-T $(0.025 \%)$. Samples stomached, homogenates were serially diluted in PBS and 100ul plated in duplicate on PRM agar Plates Incubated at $37^{\circ} \mathrm{C}$ for $7 \mathrm{~h}$, Plates are scanned with BARDOT and scattered pattern analyzed using DOTBAR software, Colonies were picked based on BARDOT identification for PCR confirmation. Chicken samples without inoculation were used as negative controls.

\subsection{DNA extraction and PCR analysis.}

DNA was extracted using the boiling method (Ngamwongsatit et al., 2008) PCR was performed using $B$. cereus gyrB gene specific primers (BcF: 5' GTTTCTGGTGGTTTACATGG-3';BcR: 5'TTTTGAGCGATTTAAATGC-3') for the forward and reverse primer respectively (Kuo and Chak, 1996 and Manzano et al., 2003). The PCR reaction mixture $(25 \mu \mathrm{l})$ contained $200 \mu \mathrm{M}$ of each dNTP, $2.5 \mathrm{mM}$ of $\mathrm{MgCl} 2,1 \times$ 
GoTaq Flexi buffer, 1 U of GoTaq Flexi DNA polymerase (Promega), $0.2-0.3 \mu \mathrm{M}$ of primers, and 60-90 ng of template DNA. PCR reactions were performed using the following cycling conditions: initial denaturation at $94{ }^{\circ} \mathrm{C}$ for 2 min followed by 35 cycles of denaturing at 94 ${ }^{\circ} \mathrm{C}$ for $1 \mathrm{~min}$, annealing at $54{ }^{\circ} \mathrm{C}$ for $2 \mathrm{~min}$, and elongation at $72{ }^{\circ} \mathrm{C}$ for $2 \mathrm{~min}$. Ultrapure sterile water was used as a negative control. aliquots were analyzed by electrophoresis in $1.5 \%$ agarose gel containing $1 \mathrm{ml}$ of ethidium bromide solution and visualized under UV light.

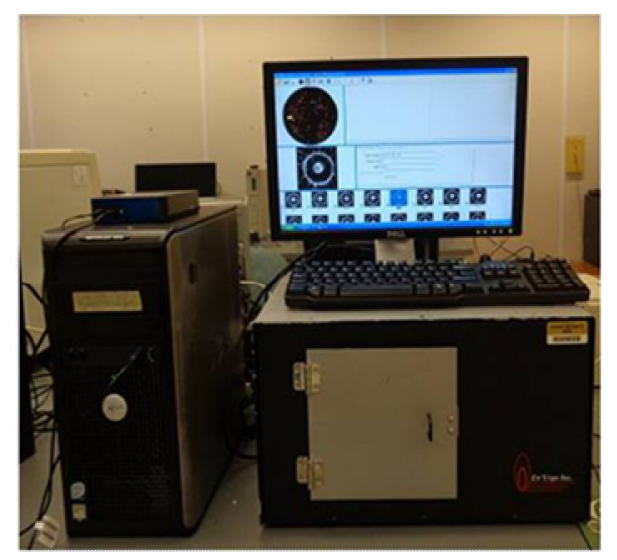

Figure 1: Photograph of a laser optical sensor BARDOT (Bacterial Rapid Detection using Optical scatter Technology)

$5 h$

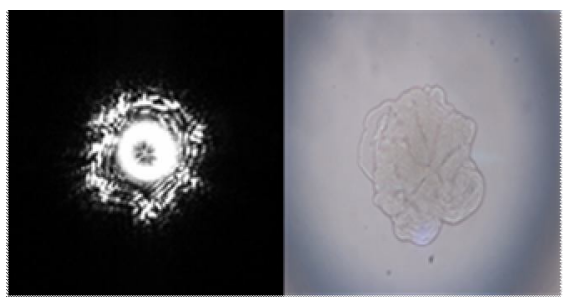

$604.6 \mu \mathrm{m}$

$7 \mathrm{~h}$

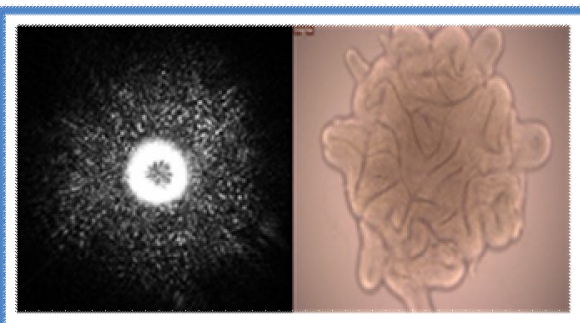

$893.5 \mu \mathrm{m}$

$10 \mathrm{~h}$

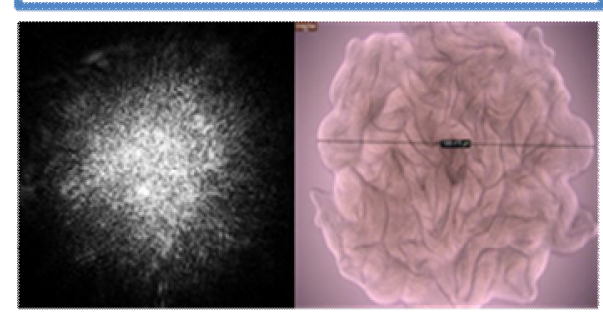

$1300.42 \mu \mathrm{m}$

Figure 2: Colony images and scatter patterns of B. cereus on PRM agar at different time points. 

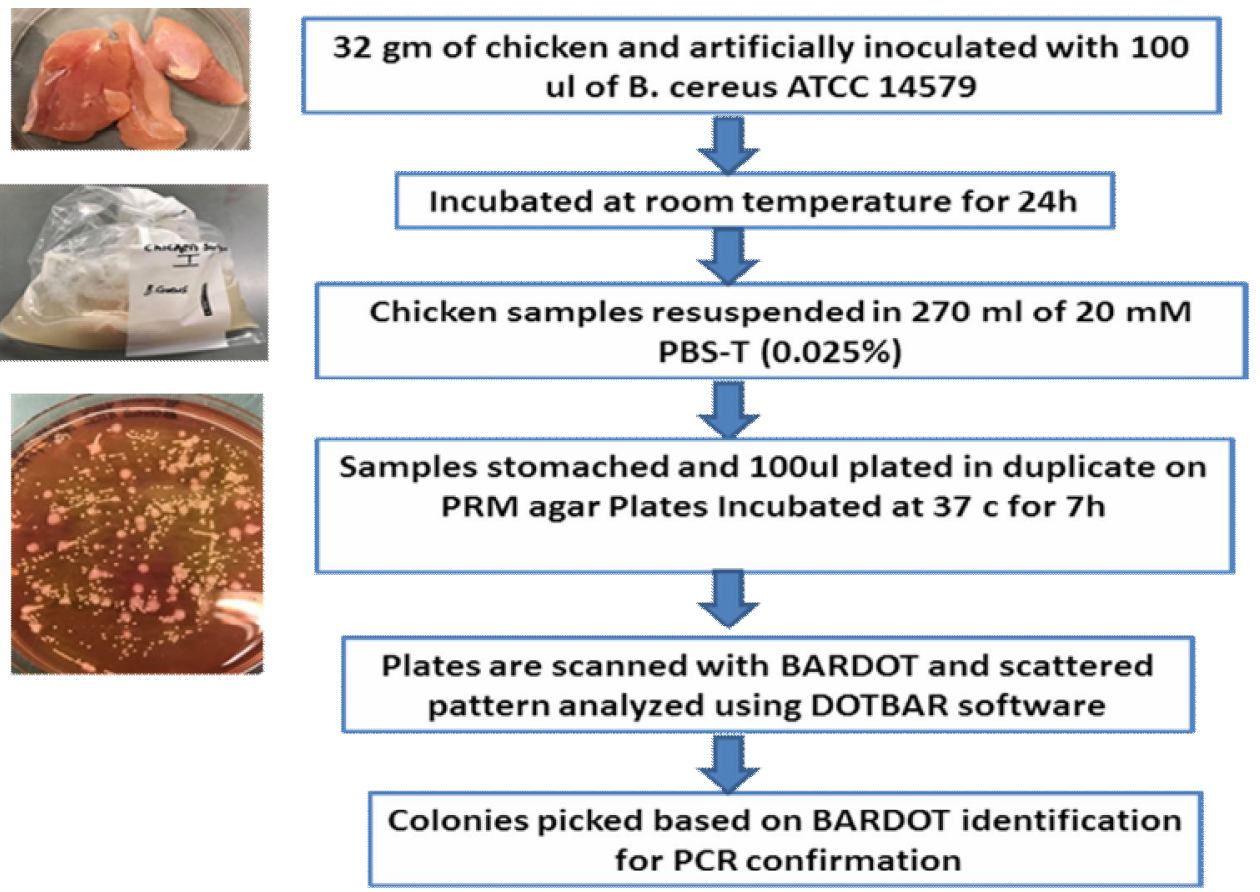

Figure 3: Flow diagram showing the procedure for the detection of $B$. cereus in chicken samples using optical scatter biosensors

\section{B. cereus ATCC 14579}
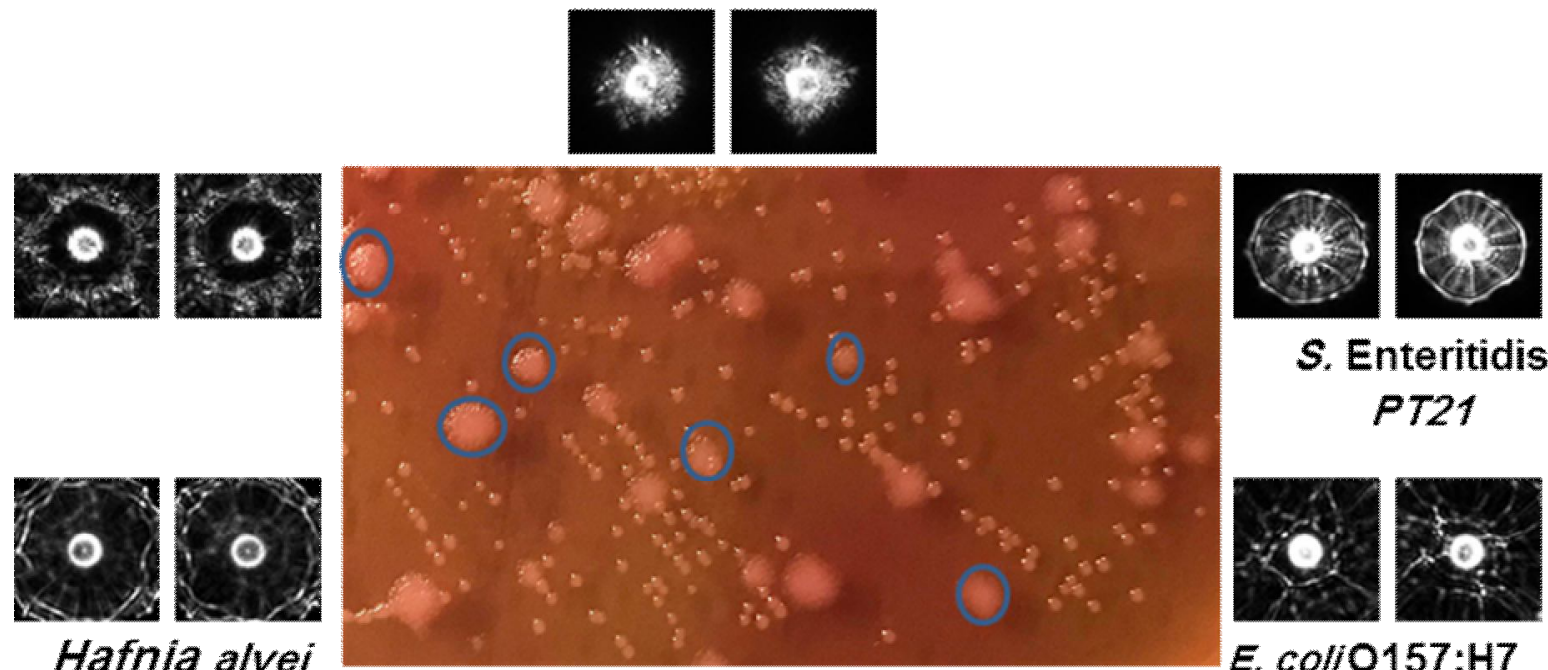

S. Enteritidis PT21

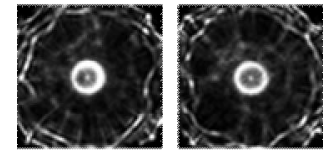

Hafnia alvei

Figure 4: Representative mixed PRM agar plate and BARDOT scatted pattern. The marked colonies are $B$. cereus, other colonies are either E. Coli 0157:H7 or S. Enteritidis PT21 


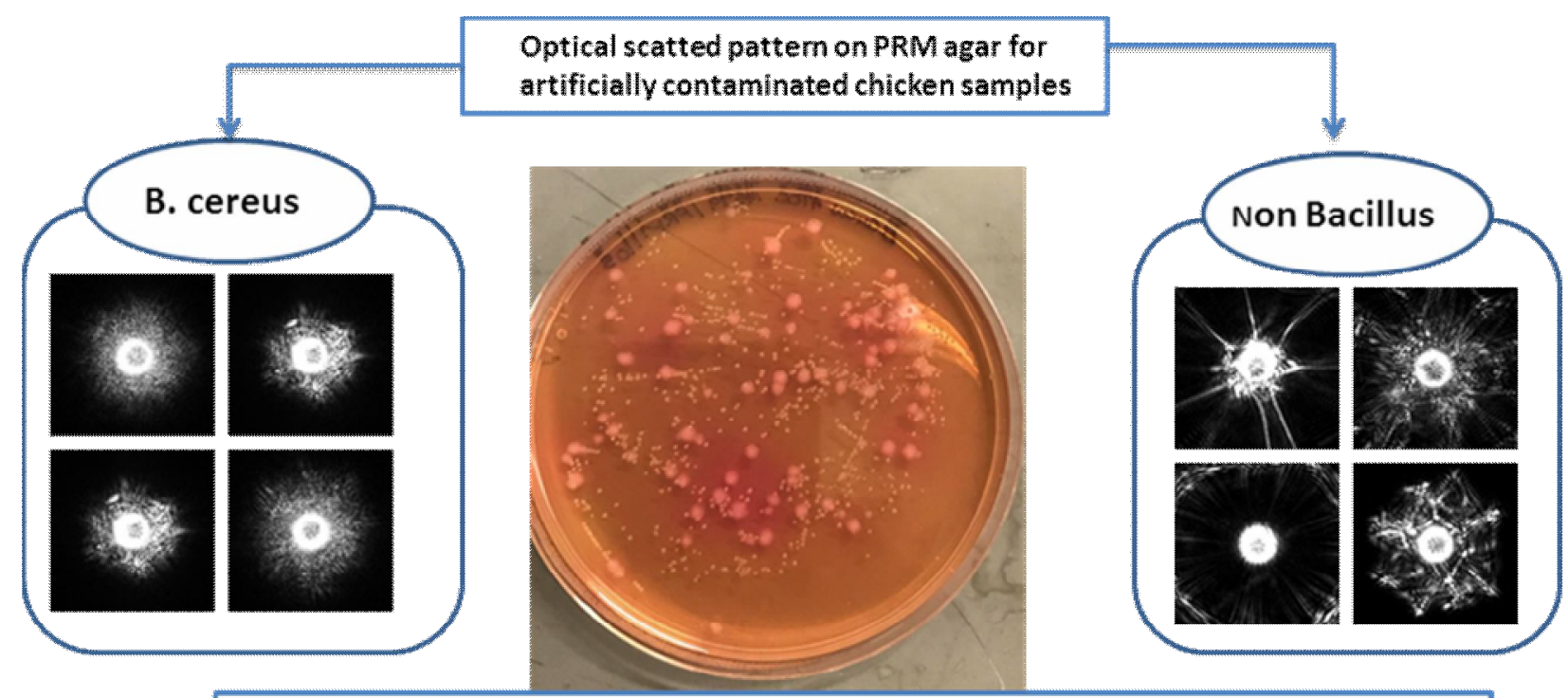

Figure 5: a-artificially contaminated chicken samples on PRM agar bScattered pattern of B. Cereus From artificially contaminated chicken samples. C-Scattered pattern of natural isolates from chickens

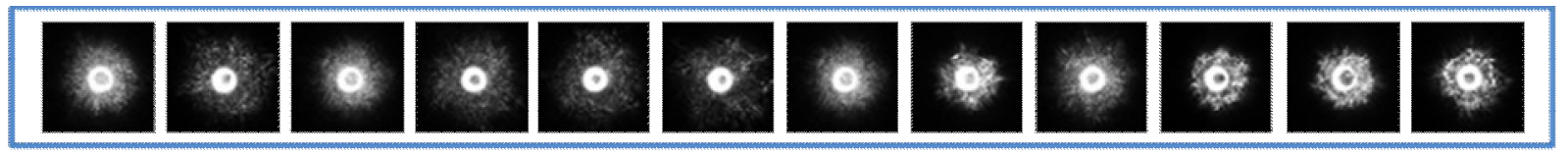

$\begin{array}{llllllllllllll}M & \mathrm{C} 1 & \mathrm{C} 2 & \mathrm{C} 3 & \mathrm{C} 4 & \mathrm{C} 5 & \mathrm{C} 6 & \mathrm{C} 7 & \mathrm{C} 8 & \mathrm{C} 9 & \mathrm{C} 10 & \mathrm{C} 11 & \mathrm{~L} 1 & \mathrm{~L} 2\end{array}$

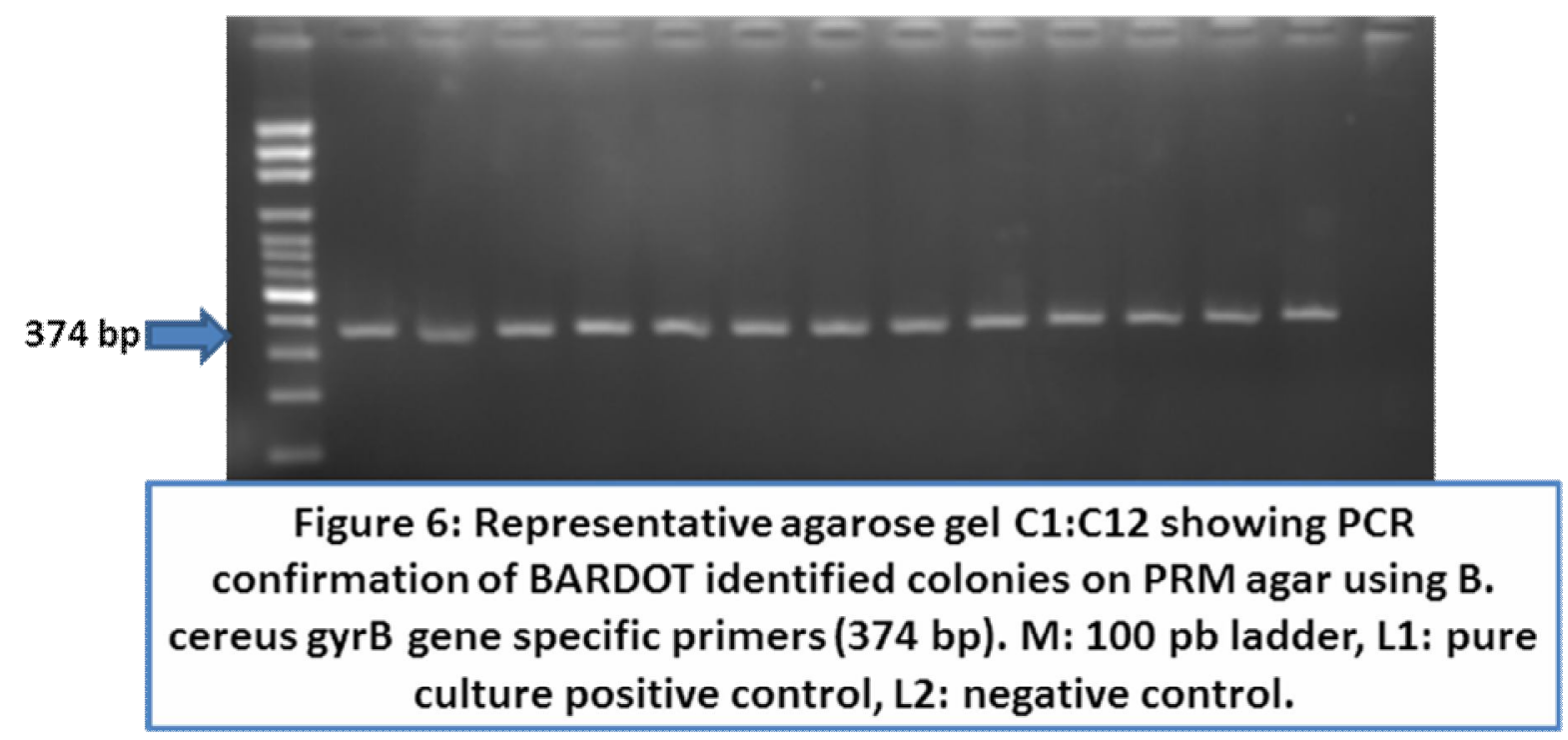




\section{RESULTS AND DISCUSSION}

Rapid and sensitive detection techniques are essential for detection and control of foodborne pathogens in food processing facilities. The conventional culture based methods provide reliable results but the analysis time, labor and the cost associated with these methods often pose a great inconvenience to industrial applications. Biosensor based detection methods are considered to be promising emerging technologies which are capable of fulfilling the current needs for providing results rapidly with improved sensitivity and specificity (Bhunia 2008 and 2011).

\subsection{BARDOT-based detection.}

For optical scattered sensor, it is essential to select an agar medium capable of yielding well differentiating scatter patterns for $B$. cereus from other foodborne pathogen and contaminants . PRM agar generated differential scatter patterns with high PPV\% on genus level using Bacillus -non Bacillus library created in our previous study, in addition to the newly added classes including (Escherichia coli O157:H7, Salmonella enterica serovar Typhimurium, Citrobacter freundii and Hafnia alvei). The Bacillus- non Bacillus scatter image library helps detect $B$. cereus at the genus level with high accuracy (PPV 95\%); this results comes in agreement with results obtained by (Singh et al., 2015). who stated that PRM agar showed high classification accuracy on genus level for Bacillus and low PPV\% on species level between Bacillus due to overlapping scattered pattern. also as reported earlier for other foodborne pathogens (Banada et al., 2009; Huff et al., 2012; Singh et al., 2014; Tang et al., 2014 and Abdelhaseib et al.,
2016). The newly added pathogens are highly distinguishable pattern on PRM agar. However they develop the $1 \mathrm{~mm}$ characteristic colony in relatively longer time (11-15h) compared $7 \mathrm{~h}$ required by $B$. cereus to develop its pattern. this result provides time elapsed differentiation of Bacillus versus non Bacillus pattern.

\subsection{Time-resolved scatter patterns of colonies of $B$. cereus versus non Bacillus}

Time elapsed measurement for the colony diameter showed that $B$. cereus require $7 \mathrm{~h}$ to reach the targeted size to create distinguishable scattered pattern, that matched (Singh et al., 2015).

on the other hand other pathogens and contaminant require $11-15 \mathrm{~h}$ to develop $1 \mathrm{~mm}$ diameter colony and scattered pattern. As between 7-8h B. cereus developed well-defined scattered pattern when the colony size measures $(0.8 \pm 0.2 \mathrm{~mm}), 5-6 \mathrm{~h}$ after incubation the pattern still raw and small in size. ten hours later scatter pattern become grainy and majority of the pattern features were missed as the colony size reach $>1.2 \mathrm{~mm}$ (Figure 2).

\subsection{Bacillus and non-Bacillus scatter patterns}

In this section we compare the pattern created by $B$. cereus colonies on PRM agar in addition to the newly added group, Results showed that $B$. cereus creating irregular shaped small grainy pattern with outstanding spokes and lack circular ring, this pattern reflect the non-symmetrical profile, and rough colony surfaces of $B$. cereus. This scatter patterns were highly distinguishable as on the other hand all non-Bacillus cultures tested in this study were circular, symmetrical with smooth surface texture and their scattered patterns showed typical concentric rings with both $S$. 
Enteritidis PT21, S. Typhimurium and with outward spokes for Citrobacter freundii, E. coli O15:7H7 EDL 933 and Hafnia alvei. The colony scatter pattern mainly depend on genotypic and phenotypic characteristics of the colony, including but not limited to shape, consistency, and surface texture, agar media used, and the time needed to reach $1 \mathrm{~mm}$ diameter colony (Banada et al., 2009; Bae et al., 2011; Huff et al., 2012 and Singh et al., 2014).

\section{4. detection of $B$. cereus mixed cultures.}

BARDOT was successful in detecting and differentiating colonies of $B$. cereus from mixed cultures with either two pathogens or multipathogen culture mix based on scattered signature.

Total of 20 colonies ware picked up from all the culture cocktails and further confirmed using PCR $100 \%$ of the tested colonies were $B$. cereus. In details 5 colonies from each mixture (B. cereus- S. Enteritidis PT21 mix), (B. cereus- E. coli O15:7H7 EDL 933 mix), (B. cereus- Citrobacter freundii - Hafnia alvei mix) and finally (B. cereus -Citrobacter freundii-E. coli O15:7H7 EDL 933- $S$. Enteritidis PT21-Hafnia alvei mix). Time required to develop the scattered pattern was also supporting factor to differentiate the $B$. cereus. (Figure 4)

\subsection{Artificially inoculated chicken samples.}

We artificially inoculated raw chicken with $B$. cereus to simulate natural contamination, and tested the efficacy of the optical sensors to detect and differentiate $B$. cereus scattered pattern in presence of natural contamination of raw chicken. DOTBAR classification with accurately ( $>98 \%)$ identified as $B$. cereus. validation of the light scattering sensor and software analysis by PCR using $B$. cereus specific primers. In total, 20 colonies identified with BARDOT (representative images, Figure 5b) from chicken, 19 out of 20 $(95 \%)$ were confirmed by PCR as B. cereus. (Figure 5,6) However, this study demonstrates the application of light scattering sensor to detect $B$. cereus based on the signature scatter pattern and thus could be used as a rapid screening tool, which can produce results within $24 \mathrm{~h}$ starting with the food or environmental samples.

The laser optical sensor described in this section was developed as a real time, label free, non-destructive, on plate detection and identification tool for use with bacterial pathogens (Banada et al., 2007; Banada et al., 2009; Bhunia, 2011 and Huff et al., 2012). The main limitation of BARDOT based detection is that it may produce overlapping patterns of target organisms with other patterns of background flora. However, when the scatter image library was used, it produced differential identification and a cut-off value below 80\% was considered negative. Furthermore, cross validation of images for presumptive positive colonies with the scatter image library for potential background bacteria on that specific agar plate would also help improve data analysis and interpretation of results. In addition, continuous improvement in scatter patterns image library with more strains will also improve BARDOT based detection of bacteria from naturally contaminated samples.

\section{Conclusion}

The present work highlights the application of light scattering sensors to improve food safety through quick screening of food samples. The novelty of label-free on plate colony screening technology, BARDOT sensors could help screening of food products for the presence of $B$. cereus on genus level in food manufacturing, and public health laboratories. Based on the BARDOT screening results, the target pathogens can be further confirmation, moreover it provides useful 
tracking and epidemiological survey through molecular techniques, genome sequencing, and effectively respond different sanitization protocols.

\section{REFERENCES}

Abdelhaseib Maha Usama, Atul K. Singh, Matthew Bailey, Manpreet Singh, Talaat El-Khateib and Arun K. Bhunia 2016. Fiber optic and light scattering sensors: Complimentary approaches to rapid detection of Salmonella enterica in food samples. Food Control, 61:135-145.

Bachhil VN and Jaiswal TN 1988. Bacillus cereus in meats: incidence, prevalence enterotoxigenicity. J Food Sci Technol, 25(6):371-372

Bachhil VN and Negi SK 1984. Bacillus cereus in meat and meat products: public health implications control. Indian J Public Health, 28(2):68-69

Banada PP, Guo S, Bayraktar B, Bae E, Rajwa B, Robinson JP, Hirleman ED and Bhunia AK. 2007. Optical forward-scattering for detection of Listeria monocytogenes and other Listeria species. Biosens. Bioelectron, 22:1664-1671.

Banada, P.P., Huff, K., Bae, E., Rajwa, B., Bayraktar, B., Aroonnual, A., Adil, A., Robinson, J.P., Hirleman, E.D., and Bhunia, A.K. 2009. Label - free detection of multiple bacterial pathogens using light scattering sensor. Biosens. Bioelectron, 24: 1685-1692.

Bae, E., Aroonnual, A., Bhunia, A.K. and Hirleman E.D., 2011. On the sensitivity of forward scattering patterns from bacterial colonies to media composition. J. Biophotonics, 4,236-243.

Bhunia, A.K. 2008. Biosensors and bio-based methods for the separation and detection of foodborne pathogens. Adv. Food Nutr. Res., 54: 1-44.

Bhunia, A.K., 2011. Rapid pathogen screening tools for food safety. Food Technol., $65,38-43$.

Bhunia, A.K., 2014. One day to one hour: how quickly can foodborne pathogens be detected? for multiplexed detection of bio-hazardous agents. Biosens. Bioelectron, 30, 78-86.

Chen, C.H. and Ding, H.C., 2004. A colony blot immunoassay for the rapid identification of Bacillus cereus. J. Food Prot., 67, 387-390.

Dietrich, R., Moravek, M., Burk, C., Granum, P.E. and Martlbauer, E., 2005. Production and characterization of antibodies against each of the three subunits of the Bacillus cereus nonhemolytic enterotoxin complex. Appl. Environ. Microbiol., 71, 82148220.

Fricker, M., Messelhäußer, U., Busch, U., Scherer, S. and Ehling-Schulz, M., 2007. Diagnostic real-time PCR assays for the detection of emetic Bacillus cereus strains in foods and recent foodborne outbreaks. Appl. Environ. Microbiol., 73, 1892-1898.

Granum PE 1994. Bacillus cereus and its toxins. J Appl Bacteriol, 76: 61S-66S.

Granum PE 2007. Bacillus cereus. Ch 20 In: Doyle MP, Beuchat LR (eds) Food

microbiology: Fundamentals and frontiers. 3rd ed, ASM Press, Washington D.C., p. 445-455

Hafiz Y, Iqbal A, Ahmad M, Wani N and Willayat MM 2012. Prevalence of Bacillus cereus in mutton tikka and chutney samples in different seasons in 
Kashmir Valley. J Pure Appl Microbiol, 6(2):975-979.

Hedman, J. and Radstrom, P. 2013. Overcoming inhibition in real-time diagnostic PCR. Methods in Molecular Biology (Clifton, N.J.), 943, 17-48.

Homola, J., 2008. Surface plasmon resonance sensors for detection of chemical and biological species. Chem. Rev., 108, 462-493.

Huff, K., Aroonnual, A., Littlejohn, A. E. F., Rajwa, B., Bae, E. and Banada, P. P., et al. 2012. Light-scattering sensor for real-time identification of Vibrio parahaemolyticus, Vibrio vulnificus and Vibrio cholerae colonies on solid agar plate. Microbial Biotechnology, 5(5), 607-620.

Jenson I and Moir CJ 2003. Bacillus cereus and other Bacillus species. Ch 14 In: Hocking $\mathrm{AD}$ (ed) Foodborne microorganisms of public health significance. 6th ed, Australian Institute of Food Science and Technology (NSW Branch), Sydney, p. 445-478.

Kotiranta A, Lounatmaa $K$ and Haapasalo $M$ 2000. Epidemiology and pathogenesis of Bacillus cereus infections. Microbes Infect, 2(2): 189198.

Kramer JM and Gilbert RJ 1989. Bacillus cereus and other Bacillus species. Ch 2 In: Doyle MP (ed) Foodborne bacterial pathogens. Marcel Dekker, New York, p. 21-70.

Kuo, W.S. and Chak, K.F., 1996. Identification of novel cry-type genes from Bacillus thuringiensis strains on the basis of restriction fragment length polymorphism of the PCR-amplified DNA. Appl. Environ. Microbiol., 62, 1369-1377.
Larsen HD and Jorgensen $K$ 1997. The occurrence of Bacillus cereus in Danish pasteurized milk. Int J Food Microbiol, 34:179-186.

Manzano, M., Giusto, C., Iacumin, L., Cantoni, C. and Comi, G., 2003. A molecular method to detect Bacillus cereus from a coffee concentrate sample used in industrial preparations. J. Appl. Microbiol., 95, 1361-1366.

Martinez-Blanch, J.F., Sanchez, G., Garay, E. and Aznar, R., 2009. Development of a real-time PCR assay for detection and quantification of enterotoxigenic members of Bacillus cereus group in food samples. Int. J. Food Microbiol., $135,15-21$.

Montville TJ and Matthews KR (2005) Food Microbiology: An Introduction. ASM Press, Washington D.C.

Moravek, M., Dietrich, R., Buerk, C., Broussolle, V., Guinebretiere, M.H., Granum, P.E., Nguyenthe, C. and Martlbauer, E., 2006. Determination of the toxic potential of Bacillus cereus isolates by quantitative enterotoxin analyses. FEMS Microbiol. Lett., 257, 293-298.

Ngamwongsatit, P., Buasri, W., Pianariyanon, P., Pulsrikam, C., Ohba, M., Assavanig, A. and Panbangred, W., 2008. Broad distribution of enterotoxin genes (hblCDA, nhe ABC, cytK, and entFM) among Bacillus thuringiensis and Bacillus cereus as shown by novel primers. Int. J. Food Microbiol., 121, 352-356.

Rao VS, Kumar RN, Kashinath L, Bhaskar $V$ and Polasa K 2012. Microbiological hazard identification and exposure assessment of poultry products sold in various localities of Hyderabad, India. Sci World J 2012:7. doi:10.1100/2012/736040 
Schoeni JL and Wong ACL 2005. Bacillus cereus food poisoning and its toxins. Journal of Food Protection, 68(3):636:648.

Senesi S and Ghelardi E 2010. Production, secretion and biological activity of Bacillus cereus enterotoxins. Toxins 2:1690-1703

Singh AK, Sun X, Bai X, Kim H, Abdalhaseib MU and Bae E, et al. 2015. Label-free, non-invasive light scattering sensor for rapid screening of Bacillus colonies. J Microbiol Methods, 109: 56-66.

Singh, A.K., Bettasso, A.M., Bae, E., Rajwa, B., Dundar, M.M., Forster, M.D., Liu, L., Barrett, B., Lovchik, J., Robinson, J.P., Hirleman, E.D. and Bhunia, A.K., 2014. Laser optical sensor, a label-free on-plate Salmonella enterica colony detection tool. mBio 5, $\mathrm{e} 01019$.

Tang, Y., Kim, H., Singh, A.K., Aroonnual, A., Bae, E., Rajwa, B., Fratamico,
P.M. and Bhunia, A.K., 2014. Light scattering sensor for direct identification of colonies of Escherichia coli serogroups O26, O45, O103, O111, O121, O145 and O157. PLoS ONE 9, 105272.

Vilain S, Luo Y, Hildreth $M$ and Brözel V 2006. Analysis of the life cycle of the soil saprophyte Bacillus cereus in liquid soil extract and in soil. Applied and Environmental Microbiology, 72:4970-4977.

Wehrle, E., Moravek, M., Dietrich, R., Buerk, C., Didier, A. and Maertlbauer, E., 2009. Comparison of multiplex PCR, enzyme immunoassay and cell culture methods for the detection of enterotoxinogenic Bacillus cereus. J. Microbiol. Methods, 78, 265270.

Willayat MM, Sheikh GN and Misgar GR 2007. Prevalence of Bacillus cereus biotypes in raw and cooked mutton. $\mathrm{J}$ Vet Public Health, 5(2): 123-125. 


\section{الملخص العربي \\ مجسات التشتت الضوئي للكشف السريح عن جراثيم باسيلس سيريس في لحم الدجاج}

\section{مها عبد الحسيب ، ارون بونيا}

تعد باسيلس سيريس جراثيم انتهازيـة تسبب التسمم الغذائي محدثه الإسـهال أو القي وتقوم مجسات التشتت

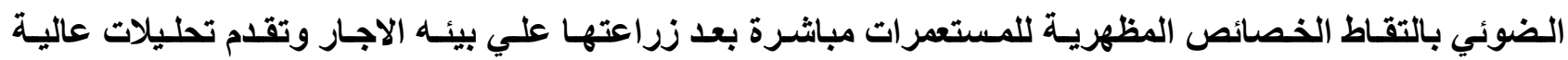

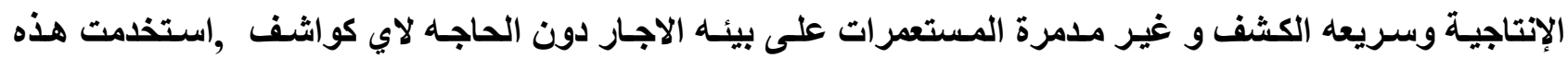
الاراسة مجسات التثتت الضوئي في الكثف عن باسيلس سيريس في العينات المختلطة وفي عينـات اللاجاج الملوثنه

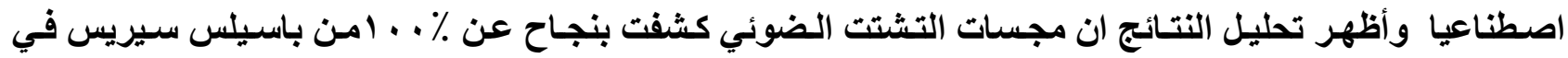

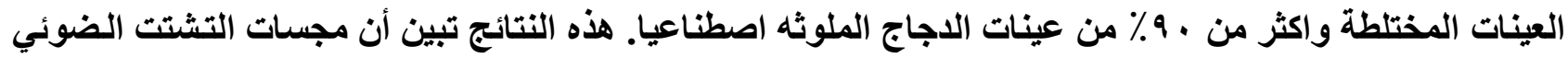
يمكن أن تستخدم كـأداة فحص لتحديـ باسيلس سيريس مـن مسبيات الأمر اض الأخري على بيئه الفينـول مـانيتول الأحمر. 